\title{
Heat Control simulation for variothermal injection moulding moulds using infrared radiation
}

\author{
Werner Berlin ${ }^{1} \cdot$ Vicky Reichel $^{1} \cdot$ André Hürkamp $^{1} \cdot$ Klaus Dröder $^{1}$
}

Received: 13 September 2021 / Accepted: 7 January 2022 / Published online: 18 January 2022

(c) The Author(s) 2022

\begin{abstract}
Mould temperature control has a significant influence on component quality and costs in the plastic injection moulding process. In the case of standard applications isothermal temperature control, in which the mould temperature is maintained at one level, is sufficient. For special applications (e.g. plastic optics; long, thin components; moulding of microstructures) variothermal temperature control using cyclically changing temperatures is beneficial. Therefore, the use of infrared radiators offers advantages in terms of achievable temperatures and investment costs but at low heating rates and efficiency. This paper therefore investigates the possibility of increasing the efficiency of energy input by infrared radiation into metals in particular into aluminium. For this purpose, a simulation model is developed. The numeric models used are validated by means of experiments. A short-wave infrared radiator is investigated, consisting of a tungsten filament in a quartz glass tube. The emitter power is varied from 1200 to $400 \mathrm{~W}$. An aluminium sample with a thickness of $10 \mathrm{~mm}$ and a square base with an edge length of $60 \mathrm{~mm}$ is investigated. The temperature is measured on the non-irradiated side in the centre of the sample surface and at a distance of $20 \mathrm{~mm}$ from it while being irradiated. For the numerical model, a ray tracing simulation is carried out in a first step, the result of which is used as a Neumann boundary condition for a thermal simulation in second step. The model created can serve as a basis for the thermal design of more complex geometries.
\end{abstract}

Keywords Injection molding $\cdot$ Infrared radiation $\cdot$ Variothermal mold heating $\cdot$ Ray tracing

\section{Introduction}

Many plastics processing methods use moulds to give a molten plastic the desired geometry. The quality of the component produced in this way also depends highly on the mould itself. In the specific case of injection moulding, the challenge is to produce uniform parts on a large scale that meet the requirements of strength, functionality, dimensional accuracy, appearance and economical

Werner Berlin

w.berlin@tu-braunschweig.de

Vicky Reichel

v.reichel@tu-braunschweig.de

André Hürkamp

a.huerkamp@tu-braunschweig.de

Klaus Dröder

k.droeder@tu-braunschweig.de

1 Technische Universität Braunschweig, Institute of Machine Tools and Production Technology, Langer Kamp 19b, 38106 Braunschweig, Germany production. The mould temperature control in particular contributes to this [1-3]. A distinction can be made between isothermal and variothermal mould temperature control. The aim of both temperature control methods is to avoid early solidification of the plastic melt during mould filling, but at the same time to cool the melt to below the demoulding temperature at which the component to be produced has sufficient structural integrity. The requirements on the mould temperature therefore change depending on the process step. During mould filling step, the mould temperature should be as high as possible in order to minimise the heat transfer between the mould wall and the plastic melt. This keeps the plastic molten for a longer time, which in turn has a positive influence on the mould filling behaviour. During the cooling time, the lowest possible mould temperature is advantageous in order to cool the hot melt to the desired temperature in the shortest possible time. This can reduce production times and increase the economic efficiency of the process. Within this context of technical restrictions and economic requirements, concepts for mould temperature control 
must be placed. With isothermal temperature control, the temperature level is kept almost constant. The set temperature is a compromise between mould filling behaviour and short cooling time. This temperature control is sufficient for most applications. However, such a static temperature control cannot be used for the production of components with long, thin flow paths, parts with high optical requirements or to reduce the stress on the plastic during injection [4]. A dynamically changing, variothermal temperature is required. For variothermal temperature control the temperature level is adjusted depending on the requirements of the respective process step and alternates between high and low temperatures. Currently, variothermal temperature control is mainly used for special applications or in micro injection moulding [5]. Due to the technical advantages, there is a need to optimise variothermal technology in the injection moulding process also with regard to economic efficiency and to make it accessible for large-scale production. An essential aspect here is the design of the temperature control with the aim to maximise the energy input for heating in order to keep the overall cycle time as short as possible. In the following, a modelling approach for the numerical representation of infrared radiation in the background of its use as a heating technology for variothermally tempered injection moulds is presented.

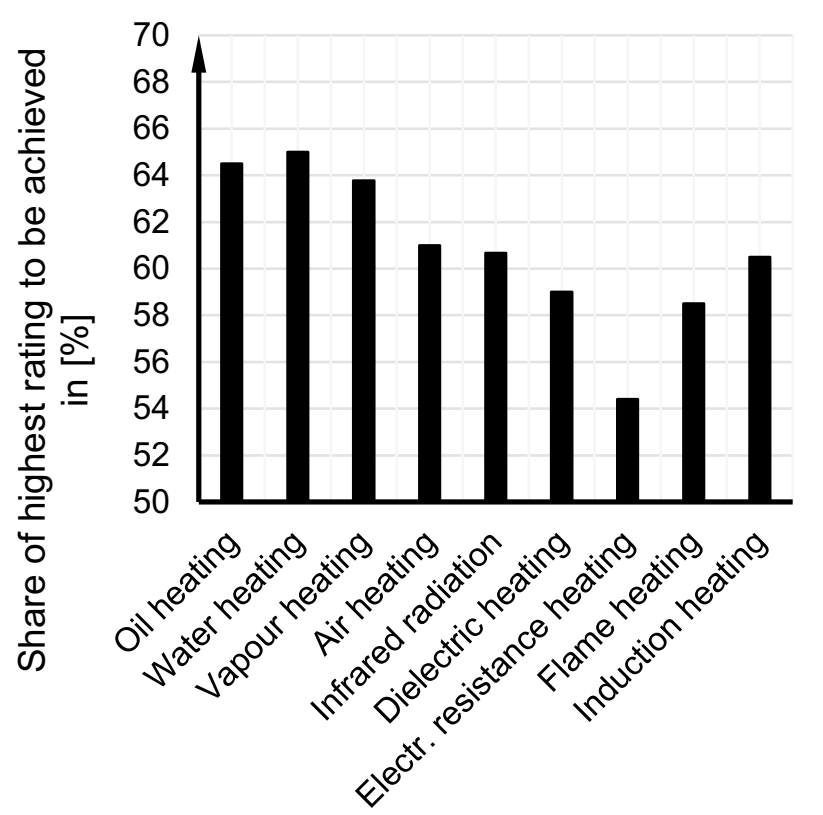

\subsection{Evaluation of variothermal heating technologies}

Variothermal mould temperature control can be realised by different media or energy sources. The most common form, following isothermally tempered moulds, is the use of fluids (oil, water, steam, hot gases) [6-12]. Other applications are induction heating [13-16], the use of resistance heating elements in the form of layer systems or ceramics [6, 17-19] and the use of radiation as an energy source (infrared radiation [20-24], microwave radiation [25], laser [26, 27]). In addition, there are also systems that use chemical energy in the combustion of gases [28, 29]. Economic and technical factors are used to evaluate temperature control systems. Figure 1 shows a summary of different evaluations for the most relevant technologies as well as the evaluation of infrared radiation in detail [15, 29-32]. For this purpose, the evaluation criteria used in the literature were clustered by topics and the ratings were standardised into a point system from 1 to 5 . The rating achieved by the respective technology is then set in relation to the theoretically achievable maximum.

The highest ratings are achieved by technologies that are also used in isothermal temperature control or use the same or similar equipment and peripherals. Infrared radiation achieves a medium to lower rating. In particular, the homogeneity of the temperature distribution and the efficiency

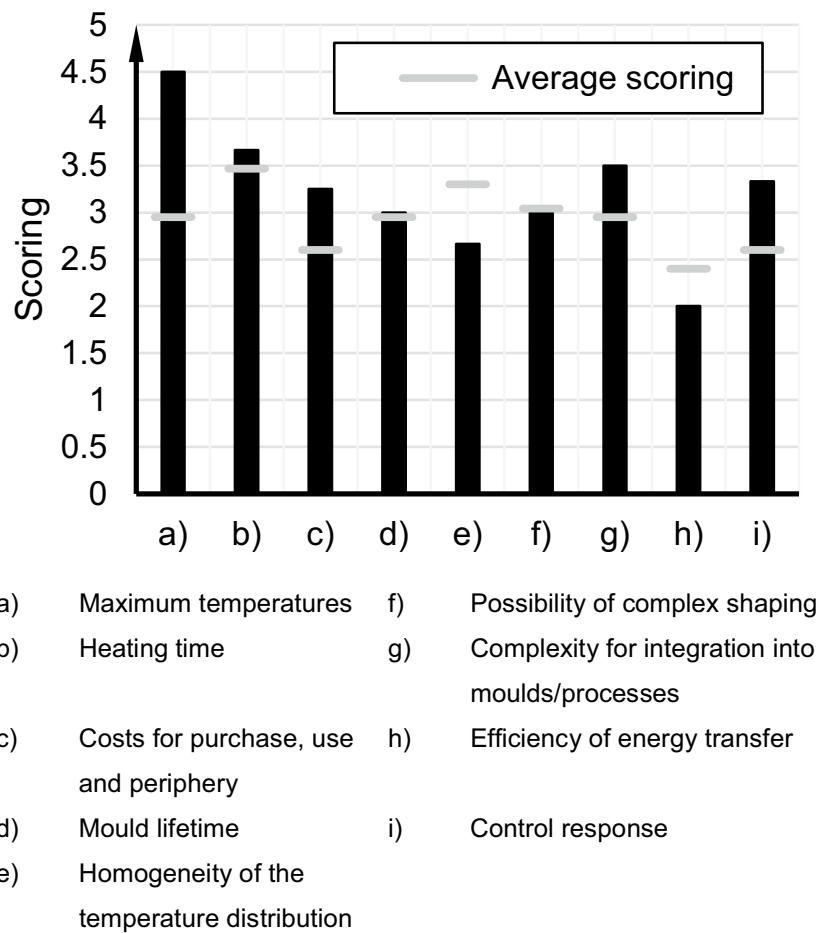

Fig. 1 Overview of the technology rating of variothermal temperature control technologies. Left: Technologies in comparison; Right: Infrared radiation in detail 
of the energy transfer are rated below average. In contrast, the rating for maximum achievable temperatures lies above average.

The energy transfer of infrared radiation happens without a medium. Therefore, infrared radiation is not bound to the restrictions of a medium (e.g. boiling or melting temperatures). Furthermore, the costs for investment, use and peripherals are also rated above average.

The aim is therefore to analyse and improve the belowaverage criteria.

\subsection{Heating concepts for injection moulds using infrared radiation}

The integration of infrared radiation in the injection moulding process for heating the mould halves can basically take place as an external or integrated radiator. With external radiators, an infrared system is moved between the halves of an open mould and heats the cavity surface [20,21, 33, 34]. The advantage is that the energy is applied directly to the surface, which is also the first to exchange heat with the plastic melt. One disadvantage is that the cavity surface usually meets the requirements of injection moulding and is polished accordingly. This increases the proportion of radiation reflected back into the environment and reduces the efficiency of the system [35]. Furthermore, the radiator standing between the mould halves blocks further mould movements and thus extends the cycle time. In addition, the resulting temperature field can hardly be homogenised, as there is no three-dimensional heat exchange at the surface. In contrast, concepts with integrated radiators are known $[23,36]$. Here, the infrared sources are installed in the mould in such a way that they can operate simultaneously to the rest of the injection moulding cycle. This means that mould movements can be carried out parallel to the heating, which does not further extend cycle times. The disadvantage is that integration is more complicated, especially on the moving mould half with for example the openings for ejectors.

With these constraints in mind, the mould concept shown in Fig. 2 is developed.

The design of the integrated radiator is being used. In addition, the optimisation approaches for improving infrared radiations rating as heating technology are consistently implemented. The mould design is divided into two parts for

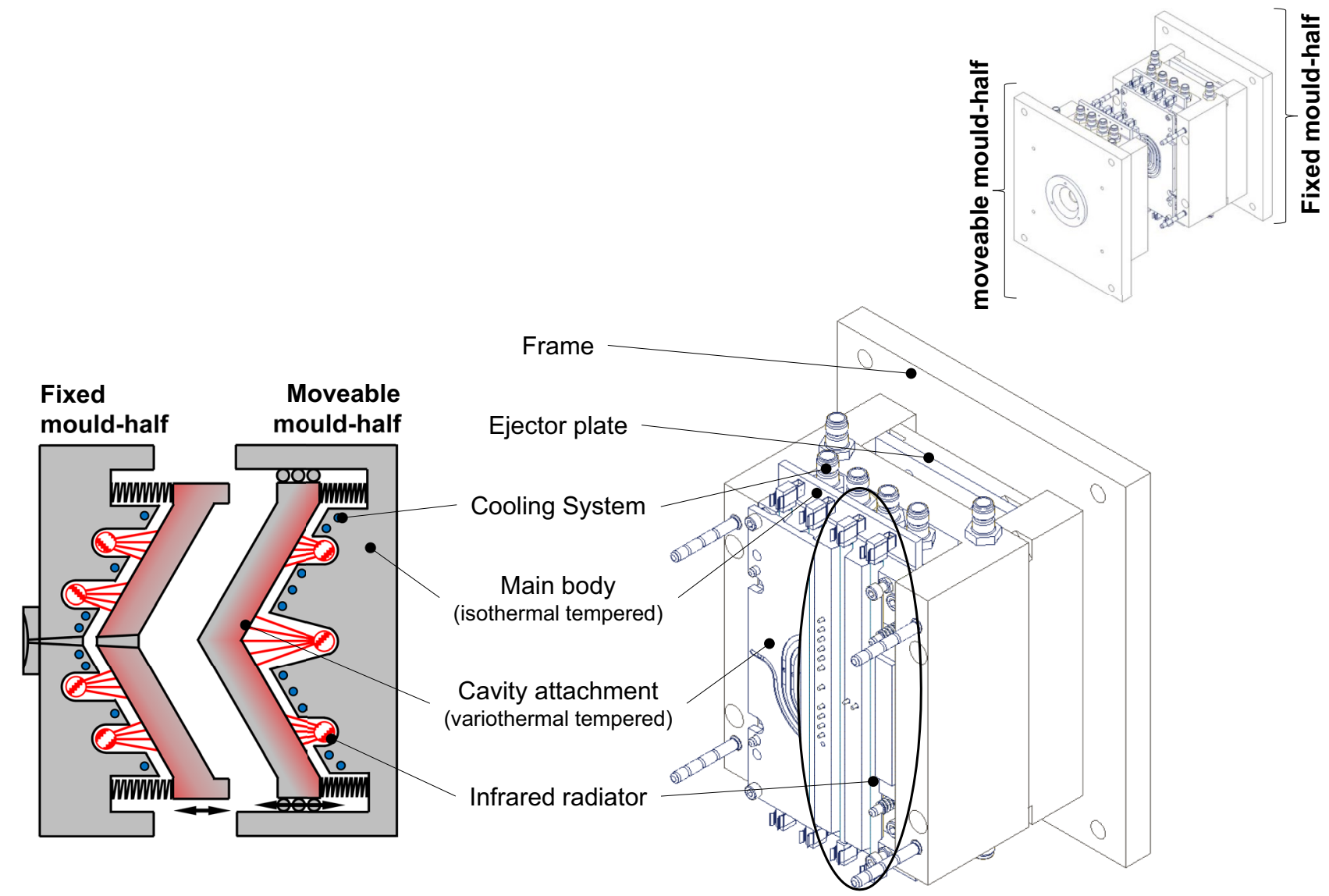

Fig. 2 Mould concept (left) and mould design (right) for the use of infrared radiation as heating system of variothermal tempering for injection moulding 
Fig. 3 Implementation of the mould concept as an injection mould on an injection moulding machine of company ENGEL

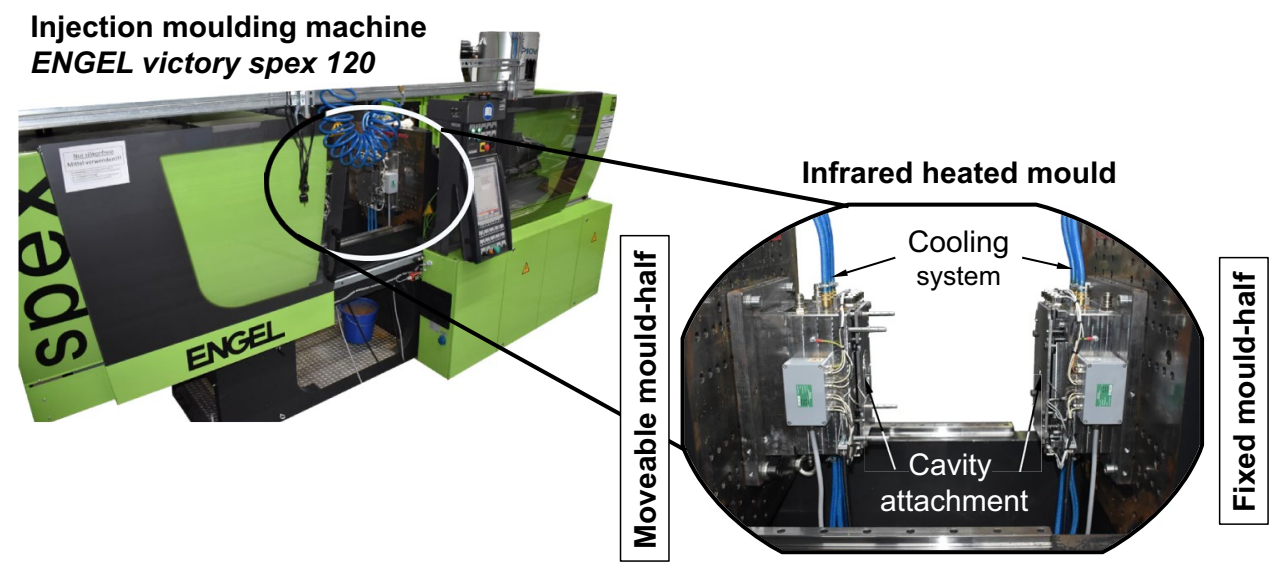

each mould half. The mould halves consist of a high-mass, isothermally cold tempered main body made of steel and a low-mass attachment made of aluminium. Infrared radiator tubes are embedded in the mould body and irradiate the back of the attachment. The attachment itself is spring-mounted and separates from the body by a gap, so that both parts are initially thermally insulated from each other. The advantage of irradiation from the back is that the irradiated surface can be optimised for energy input by infrared radiation without affecting the unirradiated cavity. Furthermore, heat is transported from the back of the attachment to the front. With a suitable selection of the thickness, the duration of the heat transport influences the cycle time only insignificantly, but causes a three-dimensional heat exchange and thus an improved homogenisation of the temperature field. Homogenisation is also supported by the choice of aluminium as a material with a higher thermal conductivity than steel. Figure 3 shows the implementation of the mould concept in the form of a demonstrator mould on an injection moulding machine from ENGEL.

The demonstrator mould initially consists of simple geometries. The aim is to reduce the cycle times already achieved and in particular the heating time. This requires optimisation of the energy absorption by infrared radiation. For this purpose, a numerical model is being developed, with the help of which the mould geometries can be adapted.

\section{Mathematical-physical modelling of infrared radiation and its interaction with metals}

Infrared radiation is part of the electromagnetic spectrum in the range from $0.78 \mu \mathrm{m}$ up to $1000 \mu \mathrm{m}$. Technically relevant are the ranges of the near infrared spectrum (up to $3 \mu \mathrm{m}$ ) and the near mid infrared spectrum (up to approx. $10 \mu \mathrm{m})$. The concept of the black body is used to describe infrared radiation. This body perfectly absorbs all incident radiation and emits it in the form of radiant energy. Planck's radiation law describes the spectral specific exitance of a black body

$\mathbf{M}_{0 \lambda}(\lambda, \mathbf{T})=\frac{2 \pi \mathbf{h} \mathbf{c}^{2}}{\lambda^{5}} \frac{1}{\mathbf{e}^{\left(\frac{\mathbf{h c}}{\lambda \mathbf{k T}}\right)}-1}$

Here $\lambda$ is the wavelength of the emitted radiation, $T$ is the temperature of the radiating body, $h$ is Planck's quantum of action, $c$ is the speed of light in a vacuum and $k$ is Boltzmann's constant. Figure 4 shows the spectral exitance for black bodies of different temperatures from 3000 to $1500 \mathrm{~K}$.

Wien's displacement law describes the progression of the maxima of each graph. It states that the maximum of the spectral radiation increases with increasing temperature and shifts towards shorter wavelengths.
Fig. 4 Different spectral Radiant exitance of a black bodies calculated by Planck's radiation law with decreasing temperatures in steps of $250 \mathrm{~K}$

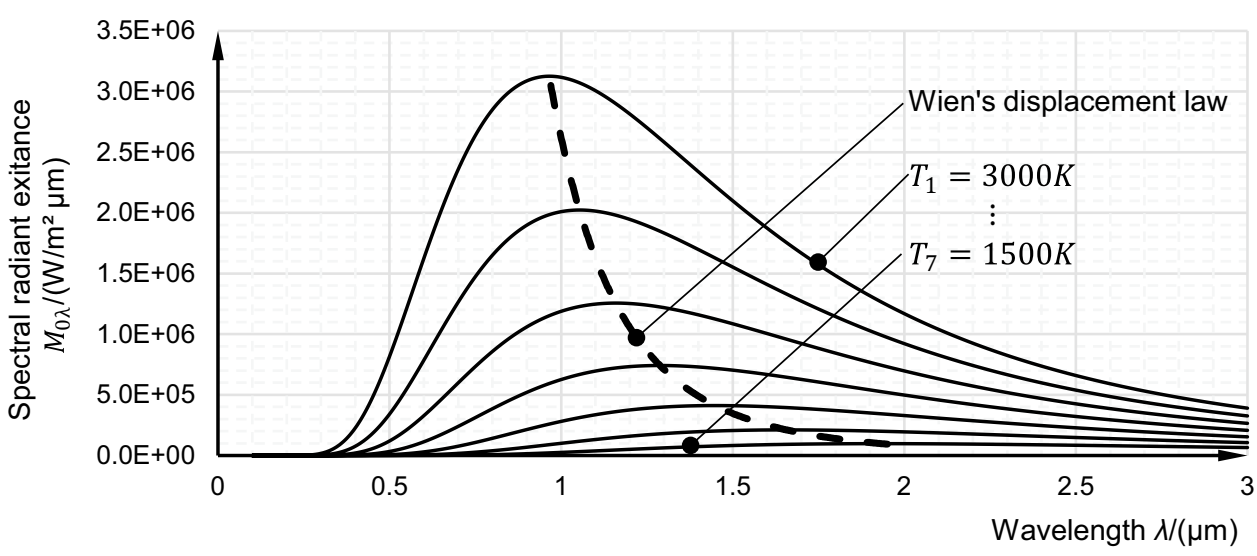


Fig. 5 Left: Calculated spectral emissivity curve for tungsten; Right: Comparison between the spectral radiant exitance of a black body and tungsten at a temperature of $2450 \mathrm{~K}$

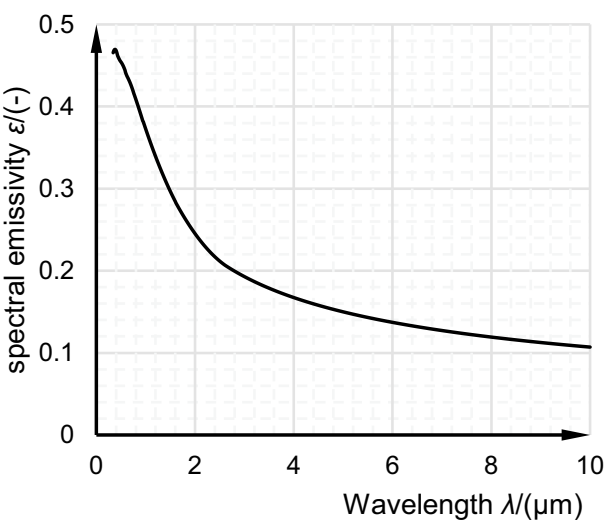

A real body differs from Plank's law of radiation and reaches a lower spectral emissivity compared to the black body at the same temperature. The ratio of the spectral exitance of the real body compared to that of a black body at the same temperature represents the spectral emissivity of the considered wavelength. Figure 5 shows the profile of the spectral emissivity of tungsten at a temperature of $2450 \mathrm{~K}$ and the comparison between the spectral exitance of tungsten and that of a black body at the same temperature.

The spectral emissivity was determined up to a wavelength of $2.6 \mu \mathrm{m}$ using a method by Russell and Jan [37]. For wavelengths beyond this up to a wavelength of $10 \mu \mathrm{m}$, the Hagen-Rubens equation is used [38]. However, the prefactor is modified in such a way that a steady gradient of the spectral emissivity is created. The spectral exitance of tungsten is obtained by multiplying the spectral exitance of the black body by the respective spectral emissivity factor for tungsten.

In the application, a tungsten filament in a radiator tube made of quartz glass has current flowing through it and is heated due to its own resistance (Fig. 6). The radiator basically consists of a quartz glass tube set into a ceramic socket at both ends. In the centre of the glass tube a tungsten filament is placed, which is held in place by support rings on the inside of the radiator tube. A $230 \mathrm{~V}$ alternating current is applied to the ends of the connecting cables. The power is adjusted by means of phase angle control.

In order to determine the resulting temperature of the filament for different electrical powers, a resistance measurement can be carried out [39]. To do this, the electrical resistance at a reference temperature (e.g. room temperature) must first be known. If the specific electrical resistance at this temperature is known, the ratio between the length of the filament and the diameter of the filament can be determined as in Eq. (2).

$\frac{\boldsymbol{l}_{0}}{\boldsymbol{A}_{0}}=\frac{\boldsymbol{R}_{0}}{\rho_{0}}$

where $l_{0}$ is the length of the filament, $A_{0}$ is the average crosssectional area of the filament and $R_{0}$ is the measured resistance in each case at the selected reference temperature. $\rho_{0}$ is the specific electrical resistance of the filament material also at the reference temperature. Due to the heating of the filament material during use, there is an expansion in the direction of the length and diameter of the filament. The diameter in turn determines the cross-sectional area. The thermal expansion can be taken into account by the linear coefficient of thermal expansion. This allows the general relationship between filament length and cross-sectional area to be determined at different filament temperatures.
Fig. 6 Design of the radiator used in the application

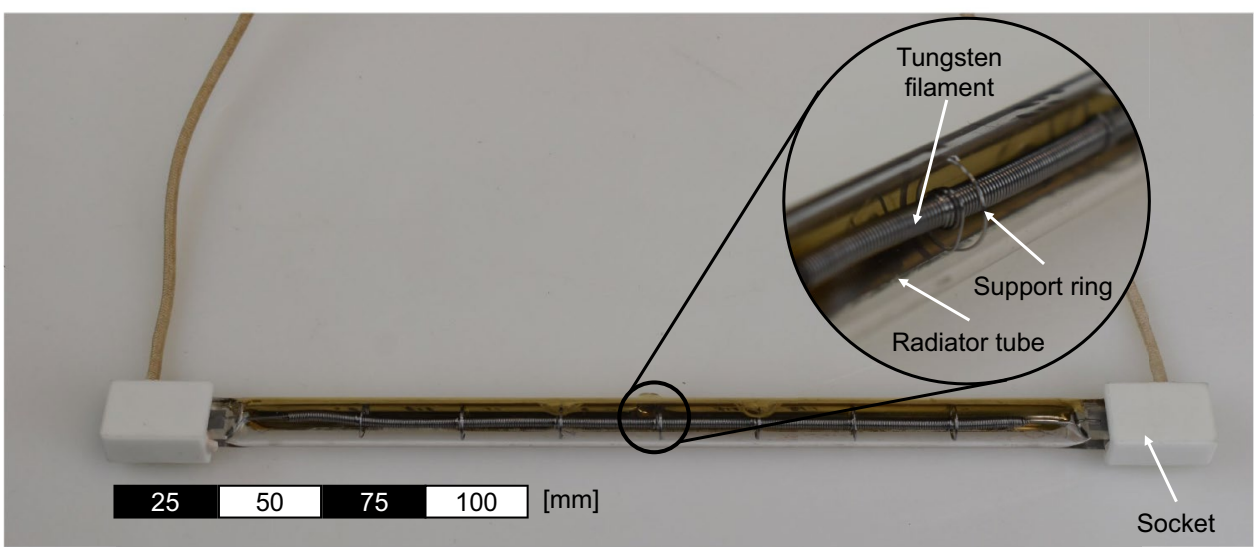


$\frac{l(\boldsymbol{T})}{A(\boldsymbol{T})}=\frac{\boldsymbol{l}_{0}}{\boldsymbol{A}_{0}} \cdot \frac{1+\cdot \alpha(\boldsymbol{T}) \cdot\left(\boldsymbol{T}-\boldsymbol{T}_{0}\right)}{1+2 \cdot \alpha(\boldsymbol{T}) \cdot\left(\boldsymbol{T}-\boldsymbol{T}_{0}\right)}$

where $l(T)$ is the length of the filament, $A(T)$ is the average cross-sectional area of the filament and $\alpha(T)$ the linear coefficient of thermal expansion each at temperature $T$. The resulting resistance at different temperatures can thus be determined.

$R(T)=\rho(T) \cdot \frac{l(T)}{A(T)}$

where $R(T)$ is the electrical resistance and $\rho(T)$ is specific electrical resistance of the filament material each at temperature $T$. With the use of the temperature-dependent material data for the linear coefficient of expansion [40] and the specific electrical resistance [41], a correlation between the temperature and the resistance that occurs can be determined (Fig. 7).

The graph can be approximated by a second-degree polynomial.

$\frac{R(T)}{R_{0}}=3 \cdot 10^{-7} \frac{1}{K^{2}} \cdot T^{2}+4.7 \cdot 10^{-3} \frac{1}{K} \cdot T-0.5431$

The factors correlate with the work of Izarra and Gitton [39].

During operation, the voltage is varied via phase angle control. For a sinusoidal voltage respectively a sinusoidal current, a time is defined within half a period in which no current flow is possible. By varying this gating time, the power can be adjusted. The current flow is interrupted again when the voltage crosses zero until the gating time has elapsed again. If the gating time corresponds to half the period time, no power is converted. The root-mean-square-(rms)-value of the AC voltage that occurs during phase angle control can be described as follows: the sine function which is around $311 \mathrm{~V}$ in $220 \mathrm{~V}$ AC networks. In principle, the rms-value of the voltage for a specific gating time is described by the maximum value of the sine function and a constant factor. The same constant factor also applies to the current, except that the maximum current value of the sine function is used to determine the rms-value. For AC voltages without phase angle control, current and voltage are in phase without phase shift. With phase angle control, the harmonic sine function is disturbed. This results in a phase shift between current and voltage, which in addition to active power generates reactive power (especially distortion reactive power). The greater the gating time, the greater the phase shift. By measuring the rms-value of the current for an ohmic load in a phase angle controlled network at different power levels, the constant factor and thus the corresponding gating time can be determined. With the gating time, the corresponding rms-value of the voltage can be calculated. The power set for current measurement corresponds to the apparent power. The actual power responsible for heating is the active power. Both are related via the phase shift angle.

$\cos (\varphi)=\frac{P}{S}$

where $\varphi$ is the shifting angle, $S$ is the apparent power and $P$ is the active power.

The active power can generally be regarded as the mean value of the time-varying power consumption of a load and thus as the mean value of the time-varying product of current and voltage.

$P=\overline{p(t)}=\overline{u(t) \cdot i(t)}$

The time dependant profiles of current and voltage can be expressed with the help of a sine wave, taking into account the phase shift of the current.

$U_{r m s} \sqrt{\frac{2}{T} \cdot \int_{t_{o}}^{t_{2} / 2} U(t)^{2} d t}=\sqrt{\frac{2}{T} \cdot \int_{t_{o}}^{t / 2} \hat{U}^{2} \sin ^{2}\left(2 \pi \frac{t_{o}}{T}\right) d t}=\hat{U} \cdot \sqrt{\frac{1}{2}-\frac{t_{o}}{T}+\frac{1}{4 \pi} \cdot \sin \left(4 \pi \frac{t_{o}}{T}\right)}$

where $U_{r m s}$ is the rms-voltage, $T$ is the period time of the sine function, $t_{o}$ is the gating time and $\widehat{U}$ is the peak voltage for

$$
u(t)=\widehat{U} \cdot \sin \left(2 \pi \cdot \frac{t}{T}\right)
$$

Fig. 7 Resistance ratio as a function of temperature

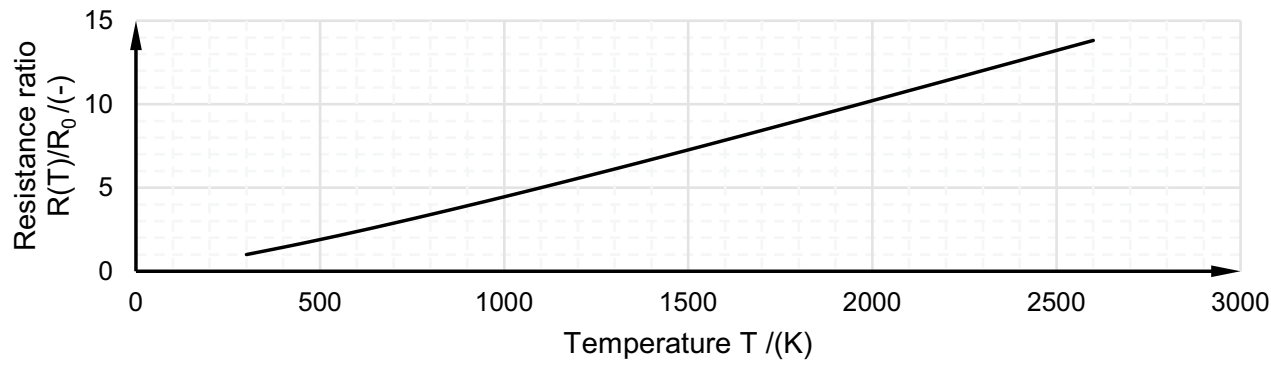


$i(t)=\widehat{I} \cdot \sin \left(2 \pi \cdot \frac{t}{T}-\varphi\right)$

The negative sign of the phase shift in the argument of the sine function of the current indicates that the current lags the voltage.

$P=\widehat{U} \cdot \widehat{I} \cdot \frac{2}{T} \int_{t_{0}}^{T / 2} \sin \left(2 \pi \frac{\mathrm{t}}{\mathrm{T}}\right) \cdot \sin \left(2 \pi \frac{\mathrm{t}}{\mathrm{T}}-\varphi\right) d t$

$P=\widehat{U} \cdot \hat{I} \cdot\left\{\left(\frac{1}{2}-\frac{t_{0}}{T}\right) \cdot \cos \varphi+\frac{1}{4 \pi} \cdot\left[\sin \varphi-\sin \left(\varphi-4 \pi \frac{t_{0}}{T}\right)\right]\right\}$

The phase shift angle is not known. Therefore, the determination of the active power is initially carried out under the assumption that there is no phase shift. From the active power determined in this way, a phase shift angle can be calculated, which in return is used for the next iteration to determine the active power. This iteration is repeated until the shift angle no longer changes. The needed resistance of the ohmic load is determined by the real part of the imaginary impedance. From the rms-values of current and voltage, the impedance can be determined.

$|\underline{Z}|=\frac{U_{r m s}}{I_{r m s}}$

where $I_{r m s}$ is the rms-value of the current. The resistance (reactance) can be determined by the phase shift angle.

$R=\operatorname{Re}\{\underline{Z}\}=\cos \varphi \cdot|\underline{Z}|$

Table 1 lists the measured rms-value of the current for the respective apparent power together with the values determined from it. In particular, this allows the temperature of the filament to be assigned to a power setting. The infrared radiators are operated in a $220 \mathrm{~V}$ electrical network at a frequency of $50 \mathrm{~Hz}$.

With the known temperature of the filament, the spectral radiant exitance of the infrared radiator can now be determined.
When radiation reaches a surface, it can interact with the irradiated body via three different mechanisms. Radiation can be reflected, absorbed or transmitted. The proportion of the radiation that is subject to the respective interaction is described by means of a coefficient

$\mathbf{A}(\lambda)+\mathbf{T}(\lambda)+\mathbf{R}(\lambda)=1$

$A$ denotes the absorbed portion of the radiation and describes the radiation energy converted into thermal energy at the surface of the irradiated body. $T$ describes the transmitted portion, which first penetrates into deeper layers of the body and is absorbed there. $R$ represents the reflected portion, which is returned back from the surface into the environment.

The following applies to the irradiation of metals with sufficient thickness [42, 43]:

$\mathbf{T}(\lambda) \cong 0$.

This simplifies Eq. (15) to:

$\mathbf{A}(\lambda)+\mathbf{R}(\lambda)=1$.

Therefore, if the spectral reflectance is known, the spectral absorptance can also be determined. Thus, the energy input by radiation into metals depends only on the absorption and the wavelength or wavelength distribution of the radiating source. Metallic surfaces can be modelled as a structure consisting of several layers. In front of the actual substrate material there are natural oxide layers and chemical impurities that influence the absorption [44]. Figure 8 shows the comparison of the degrees of reflection between pure aluminium [45] and aluminium oxide $\mathrm{Al}_{2} \mathrm{O}_{3}$ [46].

To take into account the influence of oxide layers on irradiated surfaces, the mixing rule

$\mathbf{R}_{\text {tot }}(\lambda)=\boldsymbol{\delta} \cdot \mathbf{R}_{\mathrm{ox}}(\lambda)+(1-\boldsymbol{\delta}) \cdot \mathbf{R}_{\text {bulk }}(\lambda)$

is applied. Here, $R_{t o t}(\lambda)$ denotes the spectral reflectance of the total layer structure of metal oxide and pure metal, $R_{o x}(\lambda)$ the spectral reflectance of metal oxide and $R_{\text {bulk }}(\lambda)$ the spectral reflectance of the pure metal. The factor $\delta$ describes the share of the oxide layer in the total

Table 1 Determined temperature of the filament at different power levels

\begin{tabular}{|c|c|c|c|c|c|c|c|c|}
\hline $\begin{array}{l}\text { rms-value } \\
\text { current } \\
I_{r m s} J(A)\end{array}$ & $\begin{array}{l}\text { rms-value } \\
\text { voltage } \\
U_{r m s} /(V)\end{array}$ & $\begin{array}{l}\text { apparent power } \\
S /(\text { VA) }\end{array}$ & $\begin{array}{l}\text { active power } \\
P /(\mathrm{W})\end{array}$ & $\begin{array}{l}\text { phase shift } \\
\text { angle } \\
\varphi /\left(^{\circ}\right)\end{array}$ & $\begin{array}{l}\text { gating time } \\
t_{0} /(\mathrm{ms})\end{array}$ & $\begin{array}{l}\text { reactance } \\
R /(\Omega)\end{array}$ & $\underset{\mathbf{R}(\mathbf{T}) / \mathrm{R}_{0} /(-)}{\text { resistance ratio }}$ & $\begin{array}{l}\text { filament } \\
\text { temperature } \\
T /(\mathbf{K})\end{array}$ \\
\hline 0 & 0 & 0 & 0 & 90.0 & 10 & 3.6 & 1.0 & 300.0 \\
\hline 1.957 & 77.6 & 400.0 & 271.8 & 47.2 & 7.17 & 26.95 & 7.49 & 1537.8 \\
\hline 3.089 & 122.8 & 600.0 & 507.7 & 32.2 & 5.94 & 33.57 & 9.32 & 1850.7 \\
\hline 4.038 & 160.5 & 800.0 & 743.6 & 21.6 & 4.79 & 36.88 & 10.24 & 2004.9 \\
\hline 4.853 & 192.6 & 1000.0 & 977.8 & 12.1 & 3.50 & 38.79 & 10.77 & 2093.3 \\
\hline 5.500 & 218.2 & 1200.0 & 1200.0 & 0 & 0 & 39.67 & 11.02 & 2134.2 \\
\hline
\end{tabular}


Fig. 8 Spectral reflectance of pure aluminium (left) and aluminium oxide $\mathrm{Al}_{2} \mathrm{O}_{3}$ (right) in the wavelength range from $0.24 \mu \mathrm{m}$ to $3 \mu \mathrm{m}$

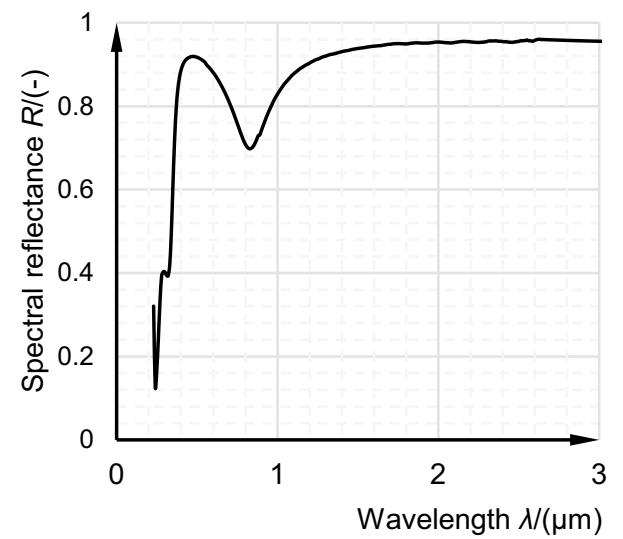

reflectance and reaches values from 0 (pure metal) to 1 (oxide only).

For translucent materials, the intensity of the radiation decreases with increasing penetration depth. According to Lambert-Beer's law, the following applies to the decrease in radiation intensity

$\mathbf{I}_{\mathbf{T}}(\lambda)=\mathbf{I}_{0}(\lambda) \cdot \mathbf{e}^{-\boldsymbol{\alpha}(\lambda) \mathbf{t}}$

where $I_{t}$ represents the radiation intensity at a certain point of the irradiated material, $I_{0}$ is the initial intensity, $\alpha$ is the absorption coefficient and $t$ is the considered thickness of the irradiated material. Thus, with a known, wavelengthdependent absorption coefficient, the intensity decrease during transmission can be determined.

\section{Simulation of heating of metals by using infrared radiation}

Based on the fundamentals for the characterisation of a radiating source and an irradiated body, the modelling of both parts is carried out. The aim is to predict the temperature distribution of an irradiated metal sample of defined thickness when irradiated by an infrared source with defined ray characteristics and position relative to the irradiated body by means of the finite element method (FEM). For this purpose, the two-step computational approach depicted in Fig. 9 is carried out.

In the first step, a ray tracing simulation is carried out. In this process, the surfaces to be irradiated and the radiating source are provided with optical properties. Due to the Lambertian radiation characteristic of the radiator, it is possible that the surfaces of the specimen that are perpendicular to the $\mathrm{x}$-axis can also be irradiated. The side surfaces perpendicular to the y-axis (shadow area) are never reached by any ray and can therefore be disregarded for heating. Due to the symmetry of the system, the power components for heating the surfaces perpendicular to the $\mathrm{X}$-axis are equal. It is therefore sufficient to evaluate one of the two surfaces in ray tracing. The emitted wavelengths of the radiation source are divided into discrete wavelengths in the range from the minimum to the maximum wavelength of interest. Each wavelength is then assigned a number of rays to be simulated limited by the specified maximum number.

The total radiated power is then distributed to the wavelength packages and within the packages again to the individual rays. Chang and Hwang proceeded in such a way
Fig. 9 Simulation sequence for the numerical determination of the temperature distribution of an irradiated sample

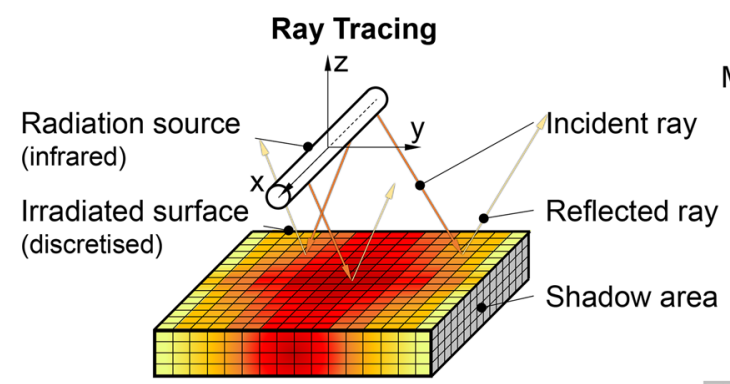

Thermal finite-element simulation Mapping as Neumann boundary condition

\section{(1)}
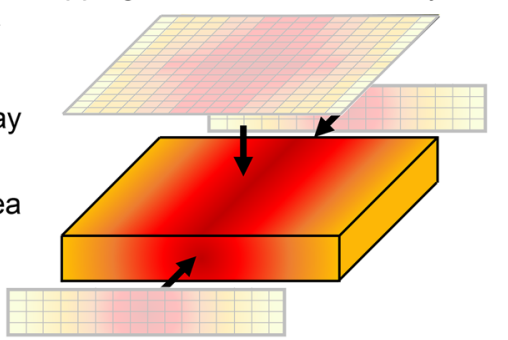

Distribution of heat flux density 
that each wavelength package was assigned the same number of rays to be simulated and each ray was assigned the same proportion of the total power of the radiator [47]. Furthermore, optical parameters were assigned independently of wavelength. This can lead to absorption or reflection maxima of the body to be irradiated not being taken into account and the power input being inaccurate. In this study, the spectral distribution of optical parameters are therefore applied.

For this purpose, a distribution method is developed based on the spectral radiation of the radiating source

$\mathbf{g}(\lambda, \mathbf{T})=\frac{\mathbf{M}_{0 \lambda}(\lambda, \mathbf{T})}{\sum_{\mathbf{i}=1}^{\mathbf{n}} \mathbf{M}_{0 \lambda}\left(\lambda_{\mathbf{i}}, \mathbf{T}\right)}$

where $g(\lambda, T)$ is the temperature-dependent distribution factor for the respective wavelength. The power $P_{r}(\lambda, T)$ transported by a single ray of a certain wavelength is determined by

$\mathbf{P}_{\mathbf{r}}(\lambda, \mathbf{T})=\frac{\mathbf{P}_{\text {tot }} \cdot \mathbf{g}(\lambda, \mathbf{T})}{\mathbf{n}(\lambda)}$

The total power of the radiator is $P_{t o t}$, the number of rays to be calculated of the respective discrete wavelength is $n(\lambda)$. This procedure defines the radiation source with regard to the radiation characteristic. In a next step, the radiation direction must be specified. Mathematically, a radiation source can be described as a Lambertian radiator. Here, every point on the surface of the radiator can emit radiation in any spatial direction of the half-space. For a discrete description, a Monte Carlo model is used in which a point on the surface of the radiator is randomly selected and the radiation angles are also randomly determined. In this way, the model maps the direction of the radiation. In order to achieve significant results, it is necessary to use a sufficient number of rays for the simulation. Assuming that each emitted ray can hit each surface element of the irradiated surface with equal probability $P_{h}$ and the requirement applies that each surface element is hit with a probability $P_{h}$ of at least one ray of each wavelength, the minimum required number of rays $k_{r}(\lambda)$ of the respective wavelength results according to

$\mathbf{k}_{\mathbf{r}}(\lambda)=\frac{\ln \left(1-\mathbf{P}_{\mathbf{h}}\right)}{\ln (1-\mathbf{p})}$

Here, $p$ is the basic probability for hitting a surface element and results as the reciprocal value of the total number of all surface elements if all elements are of the same geometry.

The result of the ray tracing simulation is the distribution of heat flux densities on the irradiated surface. Depending on the optical properties of the irradiated material, the proportion of reflected radiation is not taken into account. According to Eq. (17), only the portion absorbed on the surface remains. This is transferred to a thermal transient simulation, where the heat flux density is applied as a Neumann boundary condition. In addition, radiation losses to the environment due to the body's own radiation as a result of temperature increase and a convective heat transfer are defined. With the help of temperature-dependent material properties, the temperature distribution of the irradiated body can then be determined.

\section{Numerical results and experimental validation}

\subsection{Results of the optical simulation}

Following the simulation sequence, an optical simulation using the ray tracing software TracePro was carried out first. The simulation model follows the radiators structure as shown in Fig. 6. Figure 10 shows the structure of the model with the essential geometric dimensions. The model represents a simplification of a test setup on which the results are validated.

The setup consists of a short-wave infrared radiator installed in a reflector holder. The reflector is coated with gold. As in the actual structure (Fig. 6), the infrared radiator consists of a tube made of quartz glass in which a tungsten filament is stored in the centre. In the model, it is assumed that the filament formed as a spiral is a continuous cylinder with a diameter of $1 \mathrm{~mm}$. The support rings of the filament on the radiator tube are neglected. The quartz glass thickness is assumed to be $1 \mathrm{~mm}$. The irradiated surface is given the optical properties of aluminium and aluminium oxide according to Eq. (4) with $\delta=0.65$. The optical properties of the gold coating are taken from the TracePro database. The quartz glass to be irradiated obeys Lambert-Beer's law with a wavelength-dependent absorption coefficient [48]. Temperature-dependent radiation properties of tungsten are assigned to the filament (Fig. 4; Eq. (21)). The filament temperature at the corresponding (apparent) power is taken from Table 1. The surface to be irradiated is divided into elements with an edge length of $1 \times 1 \mathrm{~mm}$, resulting in a minimum number of rays per wavelength of 2500 with a required probability of 50\% (Eq. (22)). For the wavelength range to be simulated from $0.34 \mu \mathrm{m}$ up to $10 \mu \mathrm{m}$, the simulation of 5,000,000 rays due to symmetry conditions fulfils this requirement. The result of the ray tracing simulation for a radiator power of $1200 \mathrm{~W}$ to $400 \mathrm{~W}$ is shown in Fig. 11 .

The power of the radiator was varied in $200 \mathrm{~W}$ increments from $1200 \mathrm{~W}$ down to $400 \mathrm{~W}$. 
Fig. 10 Layout of the optical simulation model for ray tracing simulation; left: schematic illustration; right: simulation model in the TracePro software

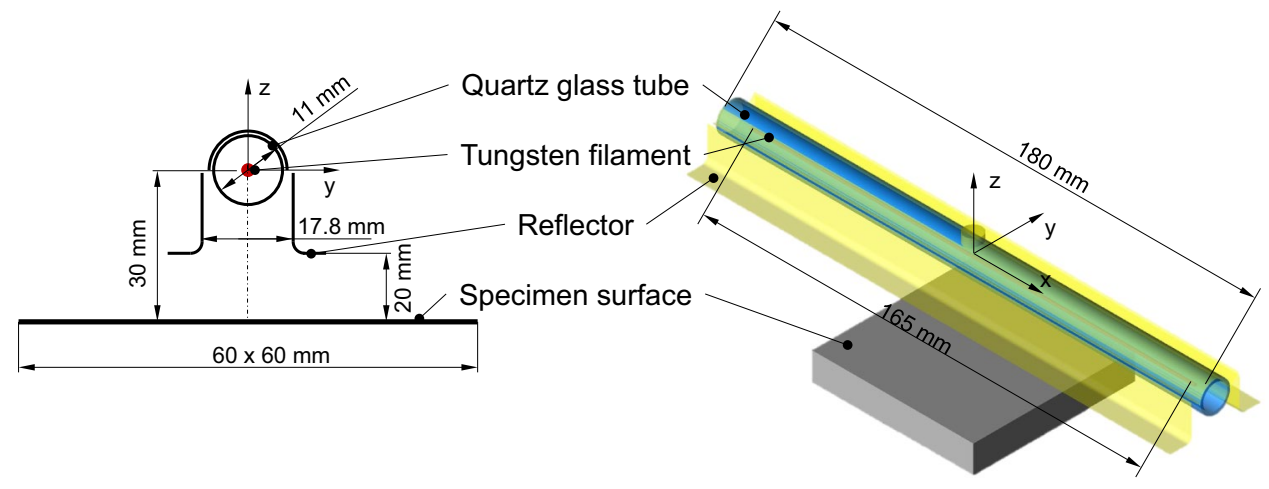

\subsection{Results of the thermal transient simulation and experimental validation}

The distributions for the heat flux density generated are transferred to a thermal finite element analysis (FEA) using the software ANSYS as boundary conditions.
Further boundary conditions were free convection on all six side surfaces of the specimen with a heat transfer coefficient of $h=50 \mathrm{~W} / \mathrm{m}^{2} \mathrm{~K}$ [49] and radiation losses on all surfaces with an hemispherical emissivity factor of $\varepsilon=0.4$ for oxidised aluminium [50]. Heat transfer by conduction can be neglected since the specimens were placed on thin

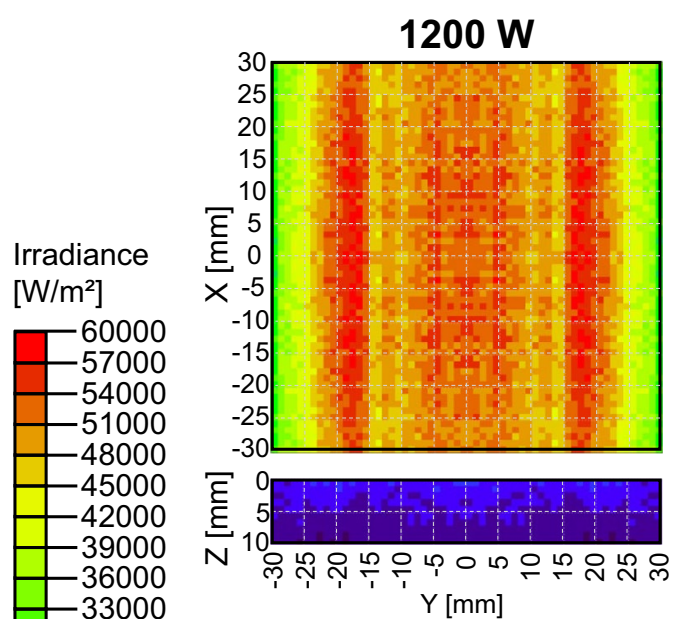

$\mathrm{Y}[\mathrm{mm}]$

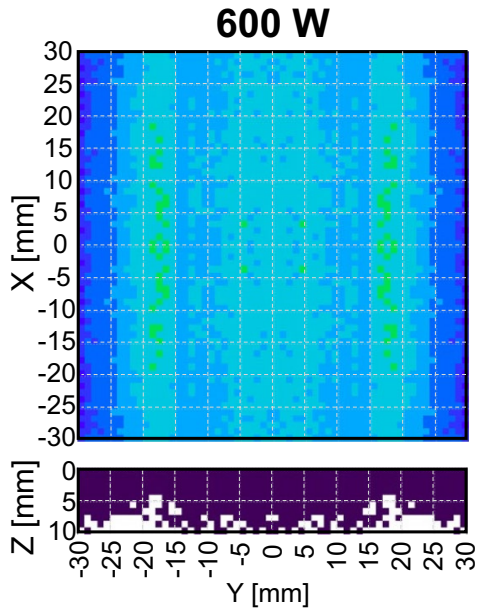

-27000
-24000
-21000
-18000
-15000
-12000
-9000
-6000
-3000
0

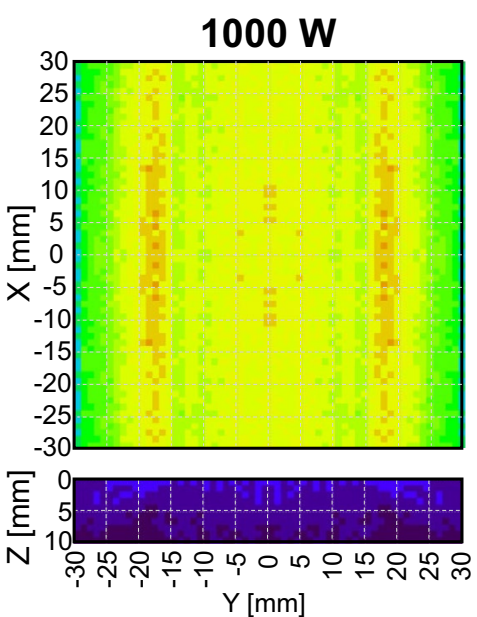

$400 \mathrm{~W}$

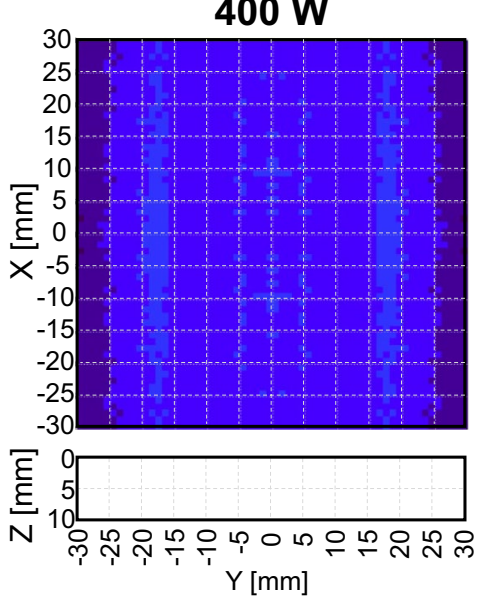

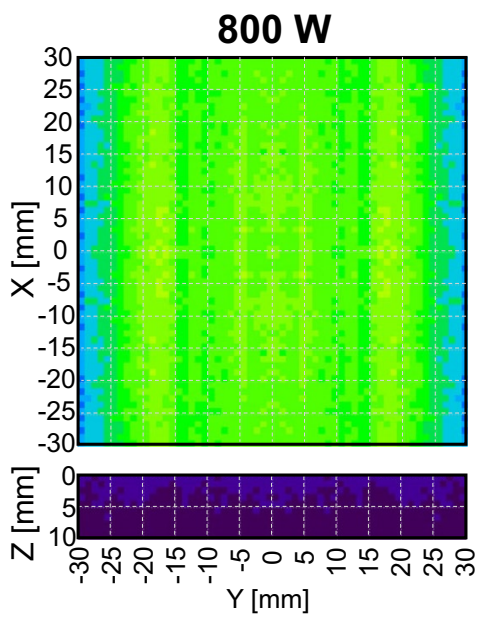

Fig. 11 Distribution of irradiance after ray tracing simulation for radiator output of $1200 \mathrm{~W}$ to $400 \mathrm{~W}$ 
Fig. 12 Temperature distribution of an aluminium sample of alloy 7075 after irradiation with an infrared source

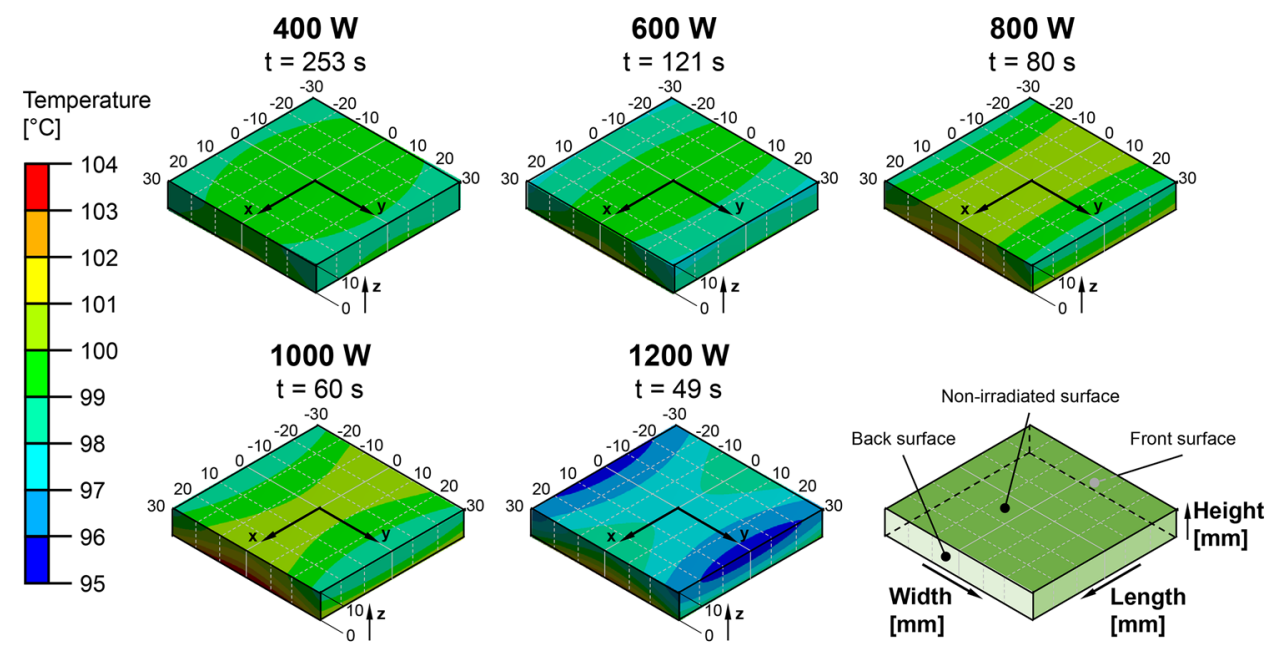

peaks in the test set-up. The material parameters specific heat capacity and thermal conductivity are deposited as a function of temperature for an aluminium alloy 7075 [51]. The density is assumed to be $\rho=2800 \mathrm{~kg} / \mathrm{m}^{3}$ [52]. The ambient temperature is set to $22{ }^{\circ} \mathrm{C}$. The model consist of a cuboid with an edge length of $60 \times 60 \mathrm{~mm}$ and a height of $10 \mathrm{~mm}$, of which the height is divided into five equally distanced layers. Each layer is discretised with elements of an edge length of $1 \mathrm{~mm}$, so that a total of 14,400 elements with 71,800 nodes are used. Figure 12 shows the three-dimensional temperature distribution after the target temperature of $100{ }^{\circ} \mathrm{C}$ has been reached in the centre of the sample on the non-irradiated side (origin of the shown coordinate system) for the power levels from 1200 to $400 \mathrm{~W}$. Furthermore, the time $t$ at which the target temperature was reached for the first time is shown. The longitudinal axis of the radiators is parallel to the $\mathrm{X}$-axis shown. The figure shows the temperature distribution of the non-irradiated side.

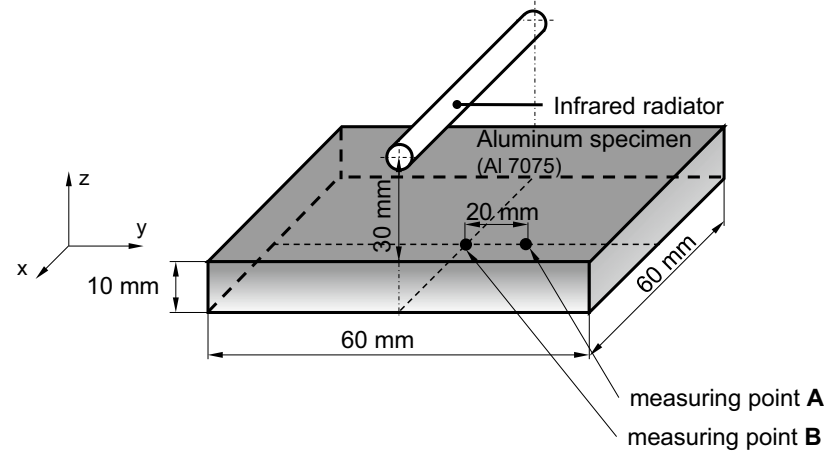

Fig. 13 Schematic overview of the measuring points in the heating test
Due to the longer irradiation time at lower power levels, the temperature field is more homogenised and thus the body is heated in larger area than at high radiator powers. However, it takes significantly longer to reach the target temperature.

To validate the numerical results, temperature profiles are measured and compared with the corresponding profiles from the simulation. For that, two pints A and B depicted in Fig. 13 are selected for the temperature evaluation. Both measuring points are located on the nonirradiated side of the sample. The first measuring point is in the centre of the non-irradiated surface, the second measuring point is shifted by $20 \mathrm{~mm}$ in the y-direction.

The measurement was carried out starting from an initial temperature of $30^{\circ} \mathrm{C}$ representing the mould base temperature in case of the application in injection moulding up to a target temperature of $100{ }^{\circ} \mathrm{C}$. The radiator power is varied in steps of $200 \mathrm{~W}$ from 400 to $1200 \mathrm{~W}$ in analogy to the numerical model. The results and the comparison with the simulation data are shown in Table 2. Furthermore, the average difference $\overline{\Delta T}$ and the maximum difference $\Delta T_{\max }$ of the temperature of the numerical results from the measurement results are given for each profile.

For low radiator power and the associated lower filament temperature, the profiles between simulation and measurement differ up to $11.6 \mathrm{~K}$. With increasing radiator power the difference decreased to $5.5 \mathrm{~K}$ and the simulation fits well the experiments. To estimate the simulation quality, a maximum difference $\Delta T_{\max }$ of $10 \%$ between the measured and simulated temperature is defined as a criterion for the prediction quality of the numerical model. For a maximum temperature of $100{ }^{\circ} \mathrm{C}$, a limit value of $10 \mathrm{~K}$ for both measuring points applies, which is fulfilled up to 
Table 2 Comparison between measured and simulated temperature curve for different radiator powers and measuring points in the range from $30{ }^{\circ} \mathrm{C}$ to $100{ }^{\circ} \mathrm{C}$

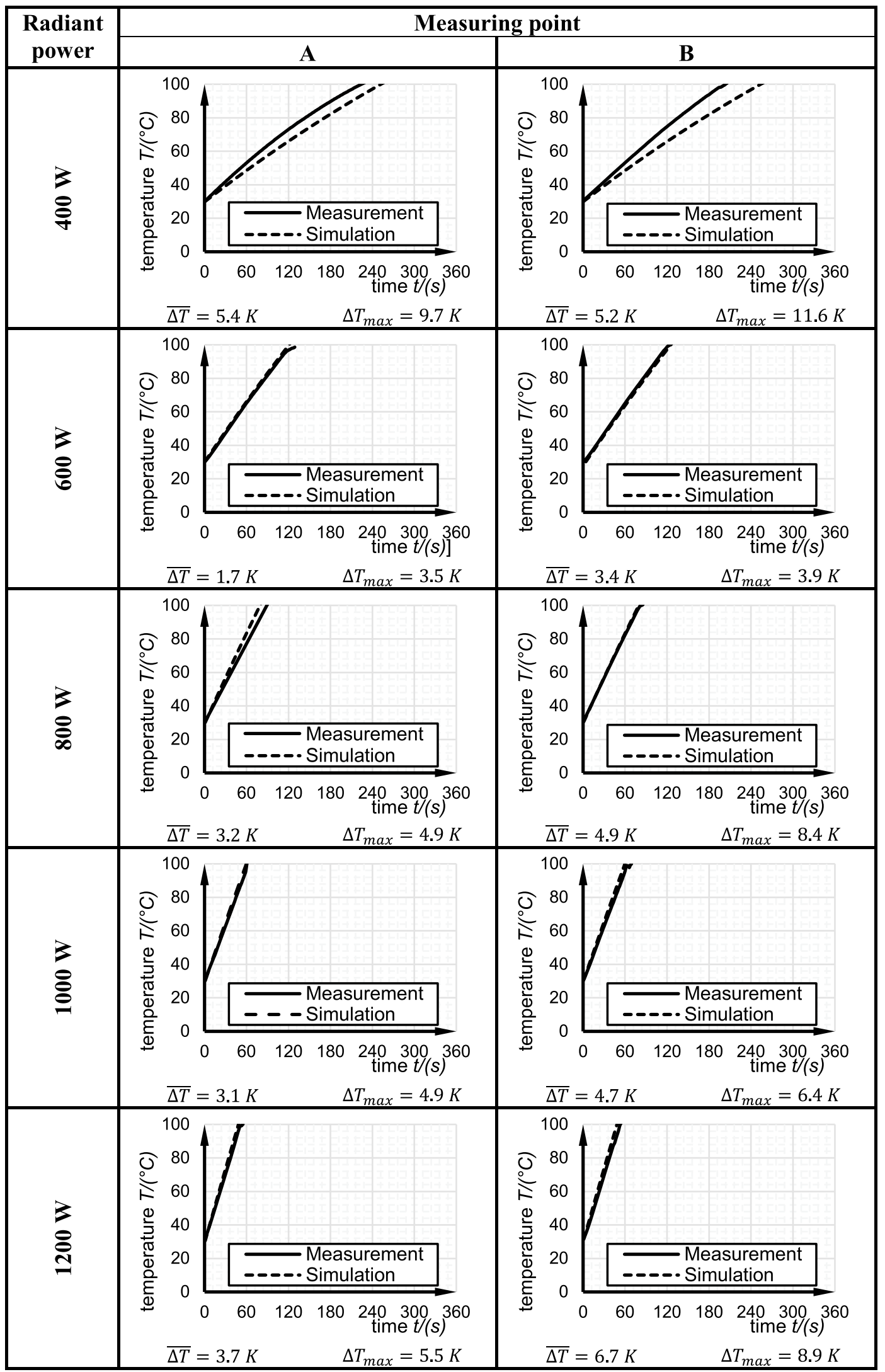


Fig. 14 Cold spots on the filament's support rings at a radiator output of $200 \mathrm{~W}$ (top) and $1200 \mathrm{~W}$ (bottom)

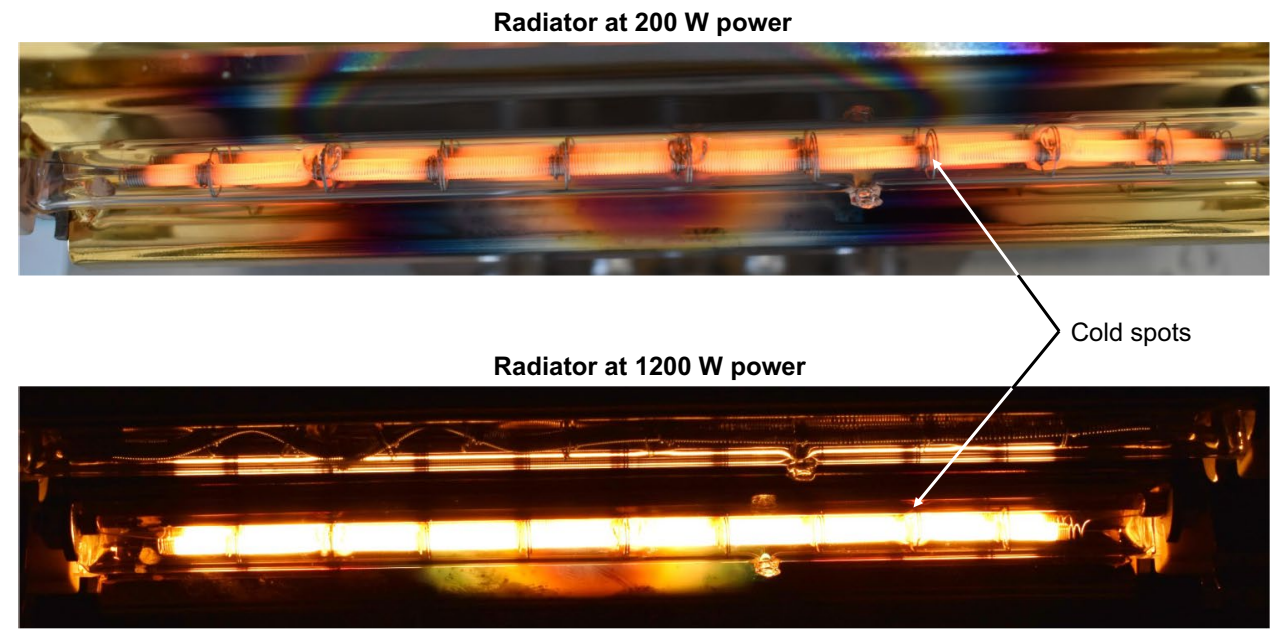

a radiator output of $600 \mathrm{~W}$. For a power level of $400 \mathrm{~W}$ the model is only partly applicable. One explanation could be the neglect of the support rings (Fig. 6). They are not taken into account in the model. The rings provide the filament with direct thermal contact to the quartz glass tube. A heat exchange takes place between the glass and the filament, which causes the temperature of the filament to be partially lower and therefore emitting with less exitance at these points according to Planck's radiation law (Fig. 4). Figure 14 shows this effect for two different radiator powers. In both cases, a darker area forms around the support rings compared to the surrounding filament, which has a lower temperature. However, these areas are wider at a power of $200 \mathrm{~W}$ than at a power of $1200 \mathrm{~W}$. The heat transfer resistance between the quartz tube and the tungsten filament limits the heat flow that can pass from the filament into the glass. At an electrical power of $600 \mathrm{~W}$ and higher, the heat flow to increase the filament temperature grows disproportionately to the heat flow into the glass due to this limitation. The temperature difference to the surrounding filament is not as high as in the case of powers less than $600 \mathrm{~W}$.

Figure 15 shows the comparison of the average heating rate at different radiator powers for both measuring points $\mathrm{A}$ and B. Within the measurement from $30{ }^{\circ} \mathrm{C}$ to $100{ }^{\circ} \mathrm{C}$, the highest intermediate heating rate of $1.46 \mathrm{~K} / \mathrm{s}$ reaches the irradiation with the highest power of $1200 \mathrm{~W}$. This heating rate corresponds to the heating rate of applications for variothermal temperature control in injection moulding with steam as the heating medium with similar energy input [53].

As the radiator power increases, the energy consumption decreases. This is because the maxima of the radiation of the radiator and the maxima of the absorption of the aluminium body continue to converge. As a result, a greater amount of energy can be absorbed in the same time.
Fig. 15 Intermediate heating rates of the simulation data for different radiator powers with indication of the required energy

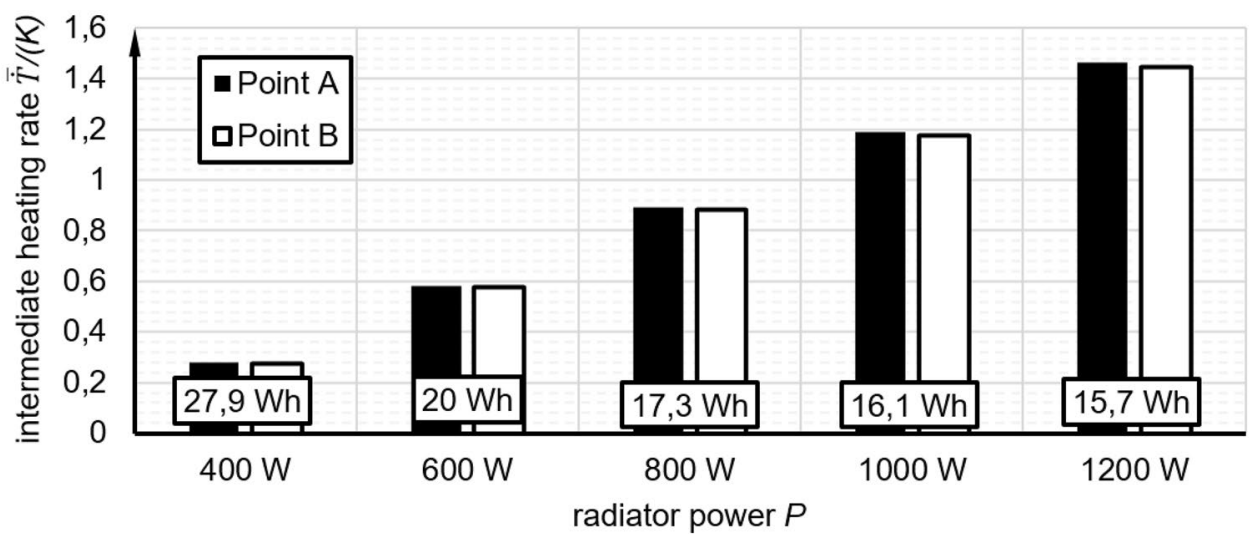


Fig. 16 Distribution of the irradiance (left) and simulated temperature distribution (right) of a sample coated with copper chromite black
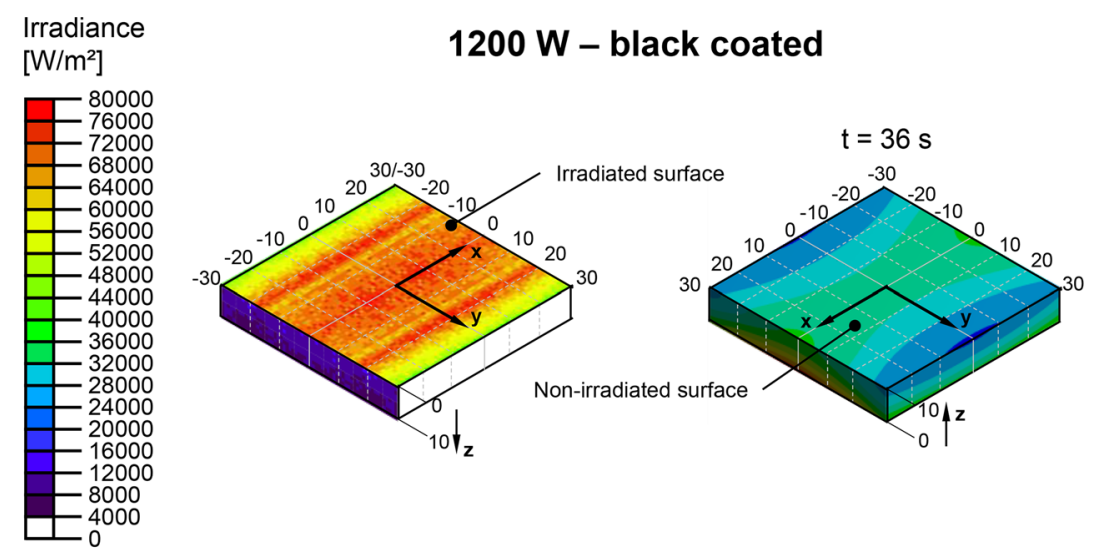

Temperature

$\left[{ }^{\circ} \mathrm{C}\right]$

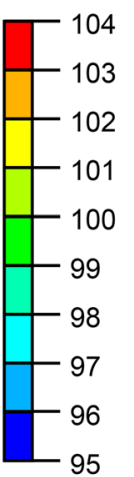

\section{Optimising energy input by surface modification}

The capability of energy absorption can be further improved by a suitable modification of the surface. The spectral absorption coefficient of the irradiated surface can be raised by using a special absorption coating [54]. For this purpose a thermally stable coating is investigated, which among other components consists of copper chromite black as a colour pigment. A spectral reflectance of 0.051 can be assumed for this coating for wavelengths in infrared region [55]. The transmittance is not taken into account due to the low spectral transmittance in relation to the spectral absorptance [56]. A simulation was carried out according to the methodology described in Sect. 3. However, instead of the spectral absorption of the aluminium and respectively aluminium oxide, the spectral absorption of the coating was assumed on the irradiated surface. Furthermore,

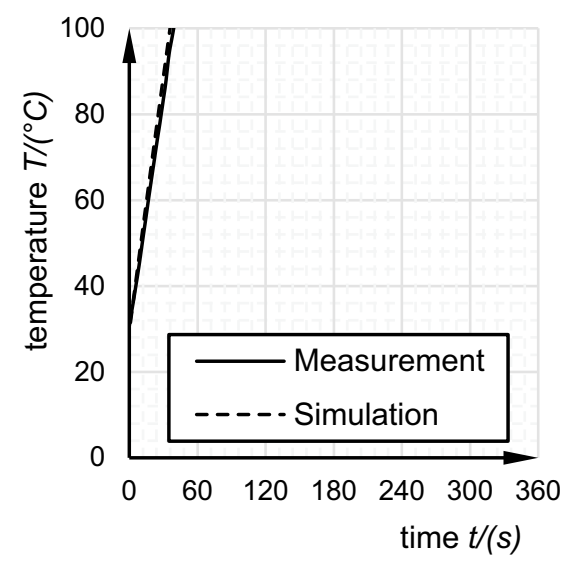

Fig. 17 Experimental validation of the heating simulation of a coated sample for maximum radiator power of $1200 \mathrm{~W}$ in the range from 30 to $100{ }^{\circ} \mathrm{C}$ an hemispherical emissivity of $\varepsilon=0.8912$ was used for the coated surface in the thermal transient analysis for heat exchange with the environment [57]. Figure 16 shows the computed distributions of irradiance and temperature distributions of a coated sample.

Figure 17 shows the experimental validation of the numerical computation of the temperature distribution for the central measuring point $\mathrm{A}$ on the unirradiated and uncoated side of the sample.

The previously defined criterion of a maximum difference between measured and calculated temperature of $10 \mathrm{~K}$ is fulfilled. The heating rate achieved could be increased from $1.46 \mathrm{~K} / \mathrm{s}$ to $1.96 \mathrm{~K} / \mathrm{s}$ compared to the uncoated sample with the same radiator power of $1200 \mathrm{~W}$. The energy consumption was reduced by $36 \%$ to $11.5 \mathrm{Wh}$ due to the coating.

Figure 18 shows the comparison of the heating rate achieved by irradiating a black painted surface by an infrared radiator with a power of $1200 \mathrm{~W}$ as well as the energy consumption used for a temperature lift of $60 \mathrm{~K}$ with other heating technologies. In particular, the model (infrared heating (model)) has already improved in comparison to the state of the art (infrared heating (SotA)). The heating rate was increased by approx. $130 \%$ and the energy consumption was reduced by approx. $66 \%$.

In general, the energy consumption is estimated conservatively. This is due to the sample geometry (square base with edge length of $60 \mathrm{~mm}$ ). The filament in the emitter has a length of $165 \mathrm{~mm}$ and therefore extends beyond the edges of the sample. As a result, only a certain proportion of the radiated rays reach the specimens surface. The remaining rays are emitted to the surroundings and do not contribute to the heating of the specimen. The heating rate is also not yet optimised. It can be increased through geometric modifications. The developed model contributes to determine optimal geometries for the respective application. 
Fig. 18 Comparison of different temperature control technologies with regard to heating rate and energy consumption for a temperature rise of $60 \mathrm{~K}$ (cf. [53])

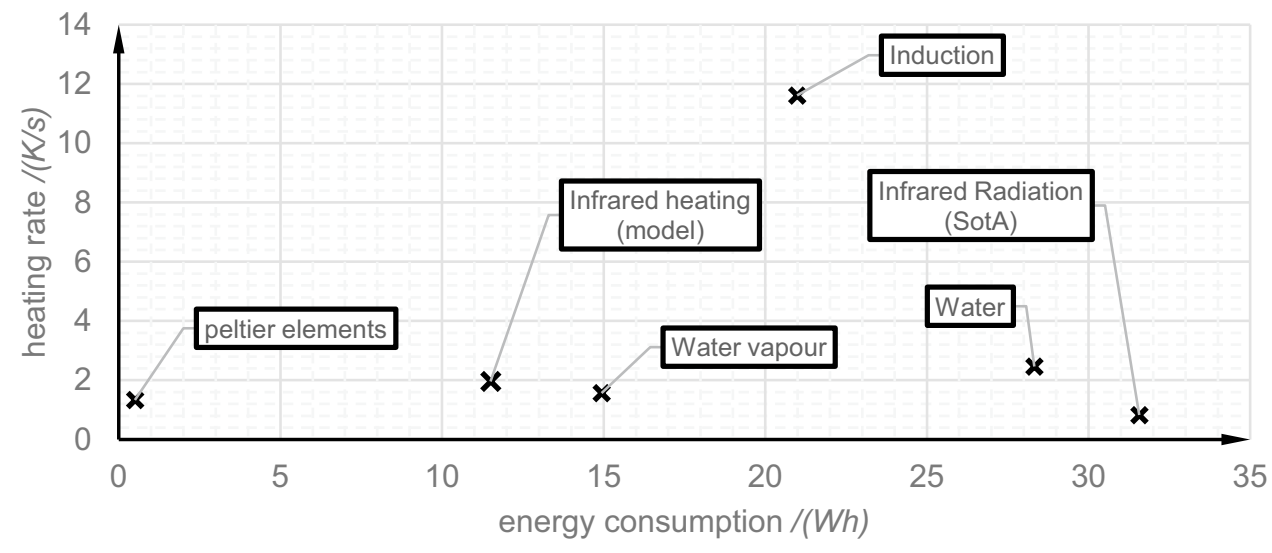

\section{Conclusion}

Compared to previous approaches, the presented simulation model takes into account the spectral distribution of optical parameters: spectral radiant exitance of the radiator and spectral reflectance as well as spectral absorptance of irradiated surfaces. This allows more specific optical effects to be investigated, especially with regard to the superposition of maxima of the absorption of irradiated bodies and maxima of the exitance of radiating sources. In Experiment and numerical simulation the radiator power was varied from 400 to $1200 \mathrm{~W}$. The filament temperature resulting in each case could be determined by considering the electrical AC system. Due to the better convergence of the maxima of the exitence of the radiator and the absorption of the irradiated aluminium surface and the phase shift that appears or the reactive power that is generated by it, the temperature rise from $30{ }^{\circ} \mathrm{C}$ to $100{ }^{\circ} \mathrm{C}$ could be achieved with increasing radiator power in a shorter time and with decreasing energy input.

The presented model was validated in the range from $30{ }^{\circ} \mathrm{C}$ to $100{ }^{\circ} \mathrm{C}$ for radiator powers of $600 \mathrm{~W}$ and higher with maximum temperature differences of $8.9 \mathrm{~K}$ to the measurement results. Power levels below $600 \mathrm{~W}$ can only be modelled to a limited extent and reach temperature deviations of up to $11.6 \mathrm{~K}$ using the presented model. In general, the numerically determined temperature curves show a higher increase compared to the measurement, especially at low radiator powers. For verification purposes, it would therefore be necessary to measure the radiation sources optically using a spectroradiometer in order to identify differences between the optical characteristics used as a basis for the model, especially at lower powers.

The heating rate of $1.46 \mathrm{~K} / \mathrm{s}$ achieved for uncoated surfaces already shows an improvement compared to the state of the art in terms of heating systems for variothermal injection moulding, but still needs to be validated for the special application case using geometries that are more complex.
To maximise this heating rate and minimising the necessary energy input, a coating using copper chromite black was also investigated and experimentally validated for the maximum radiator power of $1200 \mathrm{~W}$. By this, an increase of the heating rate to $1.96 \mathrm{~K} / \mathrm{s}$ and a decrease of the energy consumption by $36 \%$ can be achieved. Comparing these model results with the state of the art for various heating technologies, there is a high potential for the use of infrared radiation as a heating system. However, the achievable heating rates and the energy required must be evaluated for a specific application. It should also be taken into account that thermally induced stresses can occur due to the inhomogeneous temperature distribution in the irradiated parts. This leads to the deformation of mould parts, particularly for use as injection moulding moulds, which can have an effect on the dimensional accuracy of the components to be produced.

The approach presented here for numerically modelling the heating of metals by infrared radiation offers a possibility for the detailed design of heating systems in industrial applications such as injection moulding. The model is an optimisation of previous approaches and shows an increased accuracy.

Funding Open Access funding enabled and organized by Projekt DEAL. No funding was received to assist with the preparation of this manuscript.

Availability of data and material All programmes and data used to generate the findings presented in this paper are named or referenced in the text. The data used was freely accessible at the time of preparing this paper. The results presented in this paper are based on data generated in-house. If you are interested in CAD data, measurement results, or other information, please contact the corresponding author by e-mail.

\section{Declarations}

Ethics approval Not applicable.

Consent to participate Not applicable. 
Consent for publication Not applicable.

Conflicts of interest/Competing interests The authors have no relevant financial or non-financial interests to disclose.

Open Access This article is licensed under a Creative Commons Attribution 4.0 International License, which permits use, sharing, adaptation, distribution and reproduction in any medium or format, as long as you give appropriate credit to the original author(s) and the source, provide a link to the Creative Commons licence, and indicate if changes were made. The images or other third party material in this article are included in the article's Creative Commons licence, unless indicated otherwise in a credit line to the material. If material is not included in the article's Creative Commons licence and your intended use is not permitted by statutory regulation or exceeds the permitted use, you will need to obtain permission directly from the copyright holder. To view a copy of this licence, visit http://creativecommons.org/licenses/by/4.0/.

\section{References}

1. Chen S et al (2009) Feasibility evaluation of gas-assisted heating for mold surface temperature control during injection molding process. Int Commun Heat Mass Transfer 36:806-812. https:// doi.org/10.1016/j.icheatmasstransfer.2009.06.007

2. Chen Z, Turng L (2005) A review of current developments in process and quality control for injection molding. Adv Polym Technol 24:165-182. https://doi.org/10.1002/adv.20046

3. Pratap B et al (2020) Plastic injection molding and its process parameters. AIP Conference Proceedings 050053. https://doi.org/ $10.1063 / 5.0024291$

4. Kent R (2016) Quality Management in Plastics Processing. Elsevier

5. Michaeli W, Klaiber F, Scholz S (2008) Investigations in variothermal injection moulding of microstructures and microstructured surfaces. Multi-Material Micro Manufacture

6. Fu G et al (2005) A variotherm mold for micro metal injection molding. Microsyst Technol 11:1267-1271. https://doi.org/10. 1007/s00542-005-0605-6

7. Nhan PT et al (2019) Study on external gas-assisted mold temperature control for improving the melt flow length of thin rib products in the injection molding process. Adv Polym Technol 5973403. https://doi.org/10.1155/2019/5973403

8. Jeng M et al (2010) Rapid mold temperature control in injection molding by using steam heating. Int Commun Heat Mass Transfer 37:1295-1304. https://doi.org/10.1016/j.icheatmasstransfer.2010. 07.012

9. Tsai Y (2017) The effect of vapor chamber in an injection molding process on part tensile strength. Exp Tech 35:60-64. https://doi. org/10.1111/j.1747-1567.2009.00578.x

10. Wang $G$ et al (2009) Research on a new variotherm injection molding technology and its application on the molding of a large LCD panel. Polym-Plast Technol Eng 48:671-681. https://doi.org/ $10.1080 / 03602550902824549$

11. Wang $\mathrm{G}$ et al (2014) Development and evaluation of a new rapid mold heating and cooling method for rapid heat cycle molding. Int J Heat Mass Transf 78:99-111. https://doi.org/10.1016/j. ijheatmasstransfer.2014.06.062

12. Chen $\mathrm{S}$ et al (2011) Gas-assisted mold temperature control for improving the quality of injection molded parts with fiber additives. Int Commun Heat Mass Transfer 38:304-312. https://doi. org/10.1016/j.icheatmasstransfer.2010.11.001
13. Chen $\mathrm{S}$ et al (2006) Rapid mold temperature variation for assisting the micro injection of high aspect ratio micro-feature parts using induction heating technology. J Micromech Microeng 16:1783

14. Huang $\mathrm{C}$ et al (2011) The effects of various variotherm processes and their mechanisms on injection molding. IPP 26:265-274. https://doi.org/10.3139/217.2436

15. Yao D et al (2008) Rapid thermal cycling of injection molds: An overview on technical approaches and applications. Adv Polym Technol 27(4):233-255. https://doi.org/10.1002/adv.20136

16. Michaeli $\mathrm{W}$ et al (2017) Investigations in injection moulding of micro structures and microstructured surfaces. Conference on Multi-Material Micro Manufacture 3-5

17. Whiteside B et al (2003) Micromoulding: process characteristics and product properties.Plastics. Rubber and Composites 32:231239. https://doi.org/10.1179/146580103225002650

18. Jacob S (2017) Temperieren direkt an der Werkzeugwand. Mikroproduktion 5:28-32

19. Wang $G$ et al (2011) Research on optimum heating system design for rapid thermal response mold with electric heating based on response surface methodology and particle swarm optimization. J Appl Polym Sci 119:902-921. https://doi.org/10.1002/app.32771

20. Gao S et al (2017) Development of high efficiency infrared-heatingassisted micro-injection molding for fabricating micro-needle array. Int J Adv Manuf Technol 92:831-838. https://doi.org/10.1007/ s00170-017-0169-5

21. Chang P, Hwang S (2006) Experimental investigation of infrared rapid surface heating for injection molding. J Appl Polym Sci 102:3704-3713. https://doi.org/10.1002/app.24515

22. Saito T, Satoh I, Kurosaki Y (2002) A new concept of active temperature control for an injection molding process using infrared radiation heating. Polym Eng Sci 42:2418-2429. https://doi.org/ 10.1002/pen. 11128

23. Berger $\mathrm{G}$ et al (2013) More Gloss Fewer Weld Lines With Variothermal Molding. Plast Technol 59:3060-3562

24. Berger $\mathrm{G}$ et al (2011) Improving the polymer surface quality by infrared radiation driven dynamic mold temperature control. $27^{\text {th }}$ Annual Conference of Polymer Processing Society

25. Akopyan R (2007) Inventor. Microwave molding of polymers. United States patent US 7223087

26. Michaeli W, Klaiber F, Schöngart M (2010) Variothermal temperature control with laser radiation. Kunststoffe International 100:48-52

27. Michaeli W, Klaiber F (2009) Development of a system for laserassisted molding of micro- and nanostructures. In: J Vac Sci Technol B 27(3):S1323. https://doi.org/10.1116/1.3079764

28. Kim D, Kang M, Chun Y (2001) Development of a new injection molding technology: Momentary mold surface heating process. Journal of Injection Molding Technology 5:229-232

29. Su Q, Zhang N, Gilchrist MD (2016) The use of variotherm systems for microinjection molding. J Appl Polym Sci 133. https:// doi.org/10.1002/app.42962

30. Giessauf J, Pillwein G, Steinbichler G (2008) Die variotherme Temperierung wird produktionstauglich. Kunststoffe 8:87-92

31. Huber R (2016) Gewusst wann - und wie. Variotherme Temperierung bringt hohe Bauteilqualität und optimale Zykluszeit zusammen. Kunststoffe 6:72-75

32. Hinzpeter U (2009) Heiße Werkzeugoberflächen lassen Formteile erstrahlen. Kunststoffe 1:17-20

33. Peplinski J, Powers S, inventors (2013) Injection molding method with infrared preheat. United States patent US 3(943):836

34. $\mathrm{Yu} \mathrm{M}$ et al (2007) Micro-injection molding with the infrared assisted mold heating system. Mater Sci Eng, A 460-461:288295. https://doi.org/10.1016/j.msea.2007.02.036

35. Namba Y, Tsuwa H (1980) Surface properties of polished stainless steel. CIRP Ann 29:409-412. https://doi.org/10.1016/S00078506(07)61361-4 
36. Gießauf J, Maßß A, Kahveci M (2007) Inventors. Heizvorrichtung für ein Formwerkzeug. Austrian patent AT 506097B1

37. Russell M, Jan P (1984) Spectral emissivity of tungsten: analytic expressions for the 340-nm to 2.6-Imum spectral region. Appl Opt 23:975-976. https://doi.org/10.1364/AO.23.000975

38. Hagen E, Rubens H (1900) Metallic reflection. Ann Phys $1: 352-375$

39. Izarra C, Gitton J (2010) Calibration and temperature profile of a tungsten filament lamp. Eur J Phys 31:933-942. https://doi.org/ 10.1088/0143-0807/31/4/022

40. Dorogokupets P et al (1999) Optimization of experimental data on the heat capacity, volume, and bulk moduli of minerals. Petrology C/C of Petrologiia 7:574-591

41. Rumble J (ed) (2021) CRC handbook of chemistry and physics. $102^{\text {nd }}$ edition 2021-2022. CRC Press, Boca Raton, London, New York

42. Wieting TJ, Schriempf JT (1976) Infrared absorptances of partially ordered alloys at elevated temperatures. J Appl Phys 47:4009-4011. https://doi.org/10.1063/1.323224

43. Poprawe R (2005) Lasertechnik für die Fertigung. Grundlagen, Perspektiven und Beispiele für den innovativen Ingenieur; mit 26 Tabellen. Springer, Berlin, Heidelberg

44. Bergström D, Powell J, Kaplan A (2007) The absorptance of steels to Nd:YLF and Nd:YAG laser light at room temperature. Appl Surf Sci 253:5017-5028. https://doi.org/10.1016/j.apsusc.2006.11.018

45. Quazi M et al (2016) Laser-based surface modifications of aluminum and its alloys. Crit Rev Solid State Mater Sci 41:106-131. https://doi.org/10.1080/10408436.2015.1076716

46. Ennaceri $\mathrm{H}$ et al (2016) Optical properties of front and second surface silver-based and molybdenum-based mirrors. IJET 8:410413. https://doi.org/10.7763/IJET.2016.V8.923

47. Chang P, Hwang S (2006) Simulation of infrared rapid surface heating for injection molding 49:3846-3854. https://doi.org/10. 1016/j.ijheatmasstransfer.2006.04.014

48. Dvurechenskii A et al (1979) Investigation of spectral absorption coefficient of $\mathrm{KI}$ and $\mathrm{KV}$ quartz glasses in IR region to upper temperature limit. J Appl Spectrosc 31:1157-1160
49. Bergman T (2015) Introduction to heat transfer. THRM 320. Wiley

50. Engineering ToolBox (2003) Aluminum - Radiation Heat Emissivity. https://www.engineeringtoolbox.com/radiation-heat-emissivityaluminum-d_433.html. Accessed 11 Jun 2021

51. Ji S et al (2013) Effect of temperature on material transfer behavior at different stages of friction stir welded 7075-T6 aluminum alloy. J Mater Sci Technol 29:955-960. https://doi.org/10.1016/j. jmst.2013.05.018

52. eFunda Inc (2021) Properties of Aluminum Alloy AA 7075. https:// www.efunda.com/materials/alloys/aluminum/show_aluminum. cfm?ID=AA_7075\&show_prop=all\&Page_Title=AA $\% 207075$. Accessed 11 Jun 2021

53. Müller A (2006) Werkzeug- und Prozesstechnik zur Abformung von Nanostrukturen auf Kunststoffsubstraten im Spritzgießverfahren. Dissertation, Technische Universität Ilmenau

54. Berlin W et al (2019) Variothermal mold heating by infrared radiation - an interaction between material and technology. https:// doi.org/10.24355/DBBS.084-201905240945-0

55. Qin J et al (2014) The optical properties of black coatings and their estimated cooling effect and cooling energy savings potential. JPEE 02:68-75. https://doi.org/10.4236/jpee.2014.24011

56. Levinson R et al (2005) Solar spectral optical properties of pigments-Part II: survey of common colorants. Sol Energy Mater Sol Cells 89:351-389. https://doi.org/10.1016/j.solmat.2004.11. 013

57. Youn $\mathrm{Y}$ et al (2019) Effects of metal dopings on $\mathrm{CuCr} 2 \mathrm{O} 4$ pigment for use in concentrated solar power solar selective coatings. ACS Applied Energy Materials 2:882-888. https://doi.org/10. 1021/acsaem.8b01976

Publisher's Note Springer Nature remains neutral with regard to jurisdictional claims in published maps and institutional affiliations. 